Original Article

\title{
N-Acetyl cysteine mitigates histopathological changes and inflammatory genes expressions in the liver of cadmium exposed rats
}

\author{
Jalal Aala ${ }^{1}$, Asghar Beigi Harchegani ${ }^{2}$ (D), Hanieh Akhlaghi Monsef ${ }^{3}$ (D) ${ }^{2}$ Zhaleh Mohsenifar ${ }^{4}$ (D) Pirooz Ebrahimi ${ }^{5}$ (D) \\ Mohammad Reza Parvizi1,* (D) \\ ${ }^{1}$ Department of Physiology, Faculty of Medicine, AJA University of Medical Sciences, Tehran, Iran. \\ ${ }^{2}$ Department of Medical Genetics, Faculty of Medicine, Shahid Beheshti University of Medical Sciences, Tehran, Iran. \\ ${ }^{3}$ Department of Genetics, Faculty of New Sciences, Medical Science Branch, Islamic Azad University, Tehran, Iran. \\ ${ }^{4}$ Ayatollah Taleghani Educational Hospital, Faculty of Medicine, Shahid Beheshti University of Medical Sciences, Tehran, \\ Iran. \\ ${ }^{5}$ University Scientific Education and Research Network, Tehran, Iran. \\ *Correspondence: mparvizi@alumnus.tums.ac.ir
}

Received: January 8, 2021 Accepted: September 23, 2021

\begin{abstract}
This study aimed to consider the expression of Nrf2, NLRP3 and caspase 1 genes, as well as oxidative stress, and the protective role of $\mathrm{N}$-acetyl cysteine (NAC) in the liver of rats treated with cadmium (Cd). Male rats were randomly divided into five groups including G1 (control), G2 (single dose of Cd), G3 (continuous dose of Cd), G4 (single dose of $\mathrm{Cd}+\mathrm{NAC}$ ), and G5 (continuous dose of Cd + NAC). Levels of malondialdehyde (MDA) and total antioxidant capacity (TAC) were measured. Expression of Nrf2, NLRP3 and caspase 1 genes was considered using RT-PCR. NAC treatments significantly improved TAC, but decreased MDA values in rats that exposed to continuous dose of $C d(p<0.05)$. Exposure to continuous dose of $\mathrm{Cd}$ caused a significant decrease in Nrf2 expression by 2.46 -fold $(\mathrm{p}<0.001$ ), but enhanced expression of NLRP3 and Caspase 1 genes by 3.13-fold and 3.16-fold), respectively $(\mathrm{p}<0.001)$. Compared to rats that treated to continuous dose of Cd, NAC supplementation enhanced the expression of Nrf2 by 1.67 -fold $(p<0.001)$ and reduced the expression of NLRP3 and Caspase 1 genes by 1.39 -fold $(\mathrm{p}<0.001)$ and 1.58 -fold $(\mathrm{p}<0.001)$, respectively. Down-regulation of Nrf2 and overexpression of NLRP3 and caspase 1 seems to be one of the main mechanisms of Cd toxicity on liver tissue. NAC protects liver tissue against Cd-induced oxidative injuries via enhancement of Nrf2 expression and reduction of NLRP3 and caspase 1 genes.
\end{abstract}

Keywords: Nrf2, NLRP3 and caspase 1, antioxidants, cadmium, N-Acetyl cysteine, oxidative stress

\section{Introduction}

Cadmium (Cd) is a toxic element that has toxicological effects on human tissues [1]. This heavy element can cause a wide range of pathological effects in humans, especially in the liver and kidney tissues through multiple mechanisms [2, 3]. Recent evidence has indicated that Cd disrupts the biological activity of cells by enhancing the peroxidation of lipids, protein synthesis, and carbohydrate metabolism [4]. Moreover, Cd inhibits DNA repair, its methylation, and consequently enhances the risk of DNA mutation. Recent studies have suggested that oxidative stress caused by overproduction of reactive oxygen species (ROS), inflammation and subsequently apoptosis are the main mechanisms of the Cd toxicity and tissue injuries $[5,6]$.

The nuclear factor erythroid 2-related factor 2 (Nrf2) is an emerging regulator of cellular resistance to oxidants. It controls the expression of multiple antioxidants response element-dependent genes to regulate the physiological and pathophysiological outcomes of oxidant exposure. NLR Family Pyrin Domain Containing 3 (NLRP3) is a critical component of the innate immune system that triggers an immune response. Recent evidence has indicated that NLRP3 mediates caspase- 1 activation and consequently the secretion of proinflammatory cytokines such as IL-1 $\beta /$ IL-18 in response to cellular damages [7]. Therefore, it is assumed that downregulation of Nrf2 and overexpression of NLRP3 may be associated with increased inflammatory cytokines, oxidative injuries, and apoptosis. Several lines of studies have indicated that downregulation of Nrf2 and overexpression of NLRP3 might be a main reason for Cd-induced oxidative stress and toxicity in different tissue; however, the underlying mechanism is unclear.

Since oxidative stress and inflammation is considered as one of the major factors for the induction of apoptosis, antioxidant supplementation may decrease apoptosis via the inhibition of Cd-induced oxidative stress. N-acetyl cysteine 
(NAC) is a potential antioxidant that its anti-apoptotic properties have been recently studied by many researchers [8,9]. Total antioxidant capacity (TAC) and malondialdehyde (MDA) are among the most important biomarkers of oxidative stress after cadmium exposure. Previous studies have revealed that MDA which is a hallmark of lipid peroxidation is increased in the liver of rats exposed to different concentrations of cadmium [10]. Cadmium has also been introduced as a major cause of glutathione depletion and decreases total antioxidant capacity in the liver tissue [11]. Given the possible role of $\mathrm{Cd}$ in liver injury, it seems that oxidative stress induction and alterations in expression of Nrf2, NLRP3 and caspase 1 genes may be possible mechanisms of $\mathrm{Cd}$ toxicity on the liver tissue. As previous studies confirmed the antioxidant and anti-inflammatory effects of NAC, administration of this compound appears to reduce pathogenesis of Cd on hepatocytes. Therefore, this study aimed to consider the effect of $\mathrm{Cd}$ on biomarkers of oxidative stress (total antioxidant, malondialdehyde) and expression of Nrf2, NLRP3 and caspase 1 genes in Cd-treated rats. The therapeutic effect of NAC on these parameters will be also considered.

\section{Materials and Methods Animals}

Thirty male Wistar rats (8-10 weeks and 150-200 g) were bought from the Pasteur Institute of Iran in April 2019 (Tehran). All rats were kept in the lab for at least one week and then randomly divided into 5 experimental groups, including G1 (control), G2 (single dose of Cd), G3 (continuous dose of Cd), G4 (NAC + single dose of Cd at same time), and G5 (NAC + continuous dose of $\mathrm{Cd}$ at same time). Rats in each group were housed 3 per cage $(30 \times 15 \times 15 \mathrm{~cm})$ in a standard climate condition $\left(22 \pm 2{ }^{\circ} \mathrm{C}\right.$, humidity $50 \% \pm 5 \%$, and a 12:12 light/dark cycle) and had free access to food (10 g/kg/day) and tab water.

\section{Treatments}

Rats in G2 group treated with a single gavage of Cd solution ( $80 \mathrm{mg} / \mathrm{kg}$; Merck Company, German) in the $1^{\text {st }}$ day of the study. Rats in G3 group received a continuous gavage administration of Cd solution ( $2.5 \mathrm{mg} / \mathrm{kg})$ every other day for four weeks. Rats in G4 group treated with gavage administration of Cd ( $80 \mathrm{mg} / \mathrm{kg})$ and NAC (50 mg/kg; Sigma Aldrich Company, USA) solutions at a same time in the $1^{\text {st }}$ day of examination. Rats in G5 group received continuous gavage administration of Cd $(2.5 \mathrm{mg} / \mathrm{kg})$ and NAC $(50 \mathrm{mg} / \mathrm{kg})$ solutions for four weeks. The final volume of administration was increased to $1 \mathrm{cc}$ using double distilled water. Doses of cd and NAC have selected by reviewing the methodology of previous studies [12-14]. The control group (G1) fed with normal pellet and water for four weeks.

\section{Tissues and blood samples collection}

Forty and eight hours after the last treatment, rats were anesthetized with xylasine (3-5 mg/kg) and ketamine (30$50 \mathrm{mg} / \mathrm{kg}$ ). Blood samples were collected from the abdominal aorta for the measurement of Cd and oxidative stress biomarkers. Liver tissues were removed and fixed in 10\% formalin for at least 48 hours. Tissue fragments were dehydrated in graded series of ethanol, embedded in paraffin, and then sectioned using an automatic microtome at 4-5 $\mu \mathrm{m}$ thickness. Finally, the sectioned tissues were stained with haematoxylin-eosin (H\&E) and examined for morphological and histological parameters by light microscopy. A fragment of liver tissue $(\sim 200 \mathrm{mg})$ was isolated and homogenized in phosphate buffer ( $\mathrm{pH} 7.0$ ) at $4^{\circ} \mathrm{C}$ with homogenizer (Hielscher, UP100H). The homogenized tissue was centrifuged at $6500 \mathrm{~g} / 4^{\circ} \mathrm{C}$ for $15 \mathrm{~min}$ [15]. The supernatants were then collected and stored at $-80^{\circ} \mathrm{C}$ for $\mathrm{Cd}$ measurement and gene expression analysis.

\section{Oxidative stress and inflammation biomarkers}

Total antioxidant capacity (TAC) in homogenized liver tissue supernatants was determined by ferric reducing of antioxidant power (FRAP), which is discussed previously $[16,17]$. The amount of malondialdehyde (MDA) level in the liver tissue was measured using the thiobarbituric acid (TBA) method [18,19].

\section{Metal analysis}

Liver tissues ( $\sim 50 \mathrm{mg}$ ) were dried overnight at $75^{\circ} \mathrm{C}$ and then digested in approximately $10 \times$ the dry tissue mass of nitric acid. The digested samples were diluted 5-fold by deionized water. For the analysis of metals in serum, blood samples were centrifuged at $600 \times \mathrm{g}$ for $10 \mathrm{~min}$. After centrifugation, supernatants were diluted 10 -fold by deionized water. Eventually, levels of serum and liver tissue Cd were measured by atomic absorption spectroscopy (AAS; Perkin Elmer model 2380) and using standard curve.

\section{Gene expression analysis}

RNX-Plus (SinaClon; RN7713C) Kit was used to extract total RNA from homogenized liver tissue. The quantity and quality of extracted RNAs was determined using a nanodrop ND-1000 spectrophotometer (Thermo science, Newington, $\mathrm{NH}$ ). Electrophoresis on $1 \%$ agarose gel was also performed to determine the quality of extracted RNAs. Revert aid reverse 
transcriptase (Thermo science, Germ any) and random hexamer primers (Thermo science, Germ any) were used for cDNA synthesis at $42{ }^{\circ} \mathrm{C}$ for $1 \mathrm{~h}$. A Rotor Gene 6000 (Corbett Research, Australia) thermocycler in 40 cycles was applied for amplifications. Each reaction included $5 \mu \mathrm{L}$ master mix and $100 \mathrm{nM}$ primers. Primer sequences are as follow [20-22]: Nrf2, 5/-CACATCCAGACAGACACCAGT-3/ (forward), 5/-CTACAAATGGGAATGTCTCTGC-3/ (reverse); NLRP3, 5/GAGCTGGACCTCAGTGACAATGC-3/ (forward), 5/- ACCAATGCGAGATCCTGACAACAC-3/ (reverse); Caspase 1, 5/GTGTTGCAGATAATGAGGGC-3/ (forward), 5/- AAGGTCCTGAGGGCAAAGAG-3/ (reverse); and glyceraldehyde 3phosphate dehydrogenase (GAPDH), 5/-AAGTTCAACGGCACAGTCAAGG-3/

(forward); 5/-CATACTCAGCACCAGCATCACC-3/ (reverse). The levels of mRNA were normalized relative to the amount of GAPDH mRNA. The relative expression of studied genes was calculated using 2- $\Delta$ Ct method [23].

\section{Statistical analysis}

All data are presented as means \pm SD. One-Way ANOVA: Post Hoc-Tukey test was used to compare the mean of all data between groups. Data were analyzed using SPSS software (version 19). A P $<0.05$ was considered as significant.

\section{Results}

There were no abnormalities in the liver tissue of rats in G1 (control) and G2 (single dose treated of Cd) groups under histopathological examinations, but increased blood in central vein, as well as enhanced inflammatory cells in the liver parenchyma and portal space were found in the liver tissue of rats in G2 and G3 groups (treated with single and continuous doses of Cd respectively). NAC significantly reduced number of inflammatory cells in G4 and G5 groups in comparison with G2 and G3 groups (Figure 1).

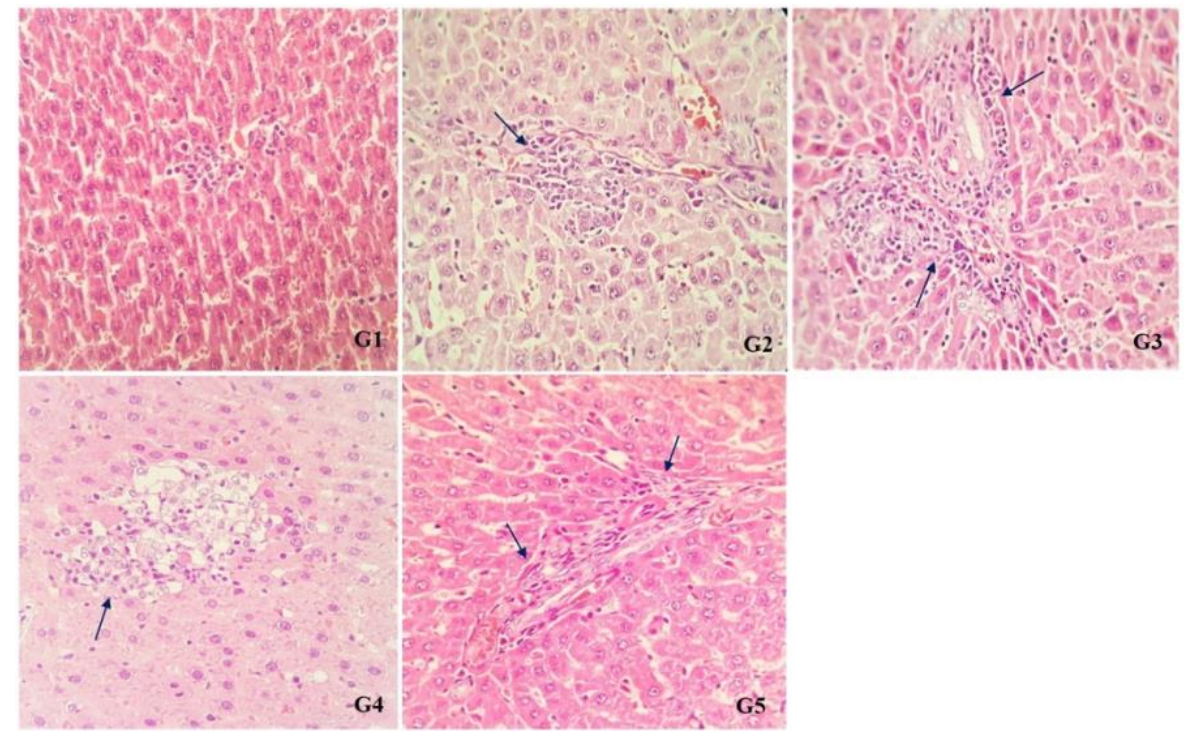

Figure 1. Sections of liver tissue from different groups. The liver of rats in control (G1) has no sign of inflammation, while sections from rats in single (G2) and continuous group (G3) showed elevated inflammatory cells. Also some apoptotic cells can be seen in continuous group (G3). Combined therapy with NAC declined number of inflammatory cells along with mild inflammation in Cd exposed groups (G4 and G5). X40 magnification.

Table 1: Comparison of the mean of FRAP and MDA between groups.

\begin{tabular}{lll}
\hline Groups & FRAP $(\mu \mathrm{g} / \mathrm{mL})$ & MDA $(\mu \mathrm{g} / \mathrm{mL})$ \\
\hline G1 & $517.09 \pm 18.06$ & $15.71 \pm 1.09$ \\
G2 & $502.87 \pm 23.34$ & $17.39 \pm 2.21$ \\
G3 & $288.86 \pm 38.66^{*}$ & $38.97 \pm 3.25^{*}$ \\
G4 & $522.43 \pm 21.31$ & $15.41 \pm 1.24$ \\
G5 & $431.77 \pm 31.85^{*}$ & $26.89 \pm 2.54^{*}$ \\
p-value & p $<0.001$ & $\mathrm{p}<0.001$ \\
\hline
\end{tabular}

G1: Control; G1: Single Cd; G3: Continuous Cd; G4: Single Cd + NAC; G5: Continuous Cd + Cd; One-Way ANOVA: Post Hoc-Tukey test was applied to compare mean value of parameters between all groups.

${ }^{*} \mathrm{p}<0.001$ compared to G1. 


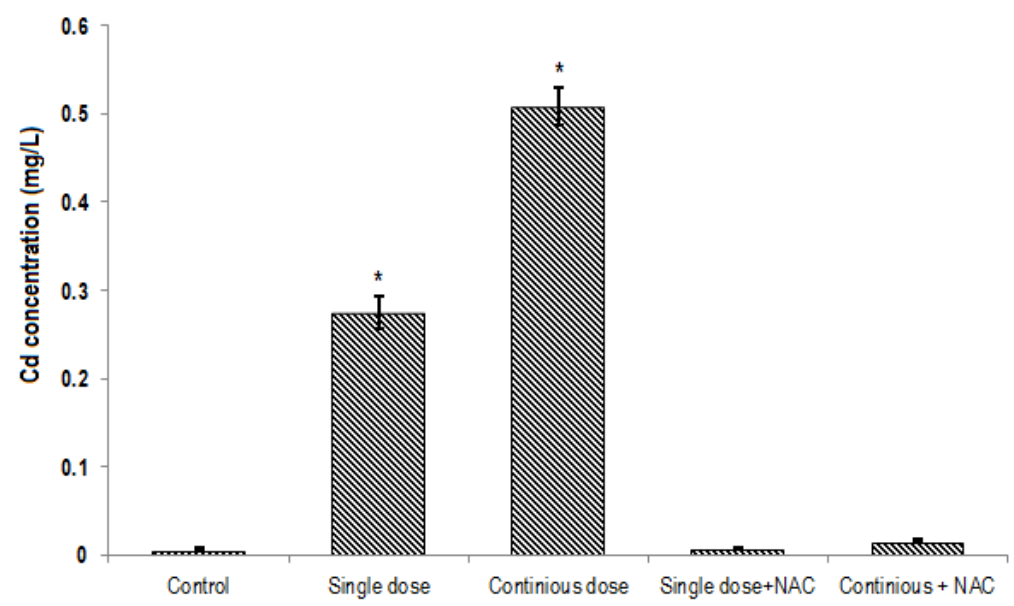

Figure 2. Comparison of the mean of $\mathrm{Cd}$ levels in the serum of rats in different groups. One-Way ANOVA: Post HocTukey test was applied to compare mean value of $\mathrm{Cd}$ between all groups. ${ }^{*} \mathrm{p}<0.001$ compared to control group.

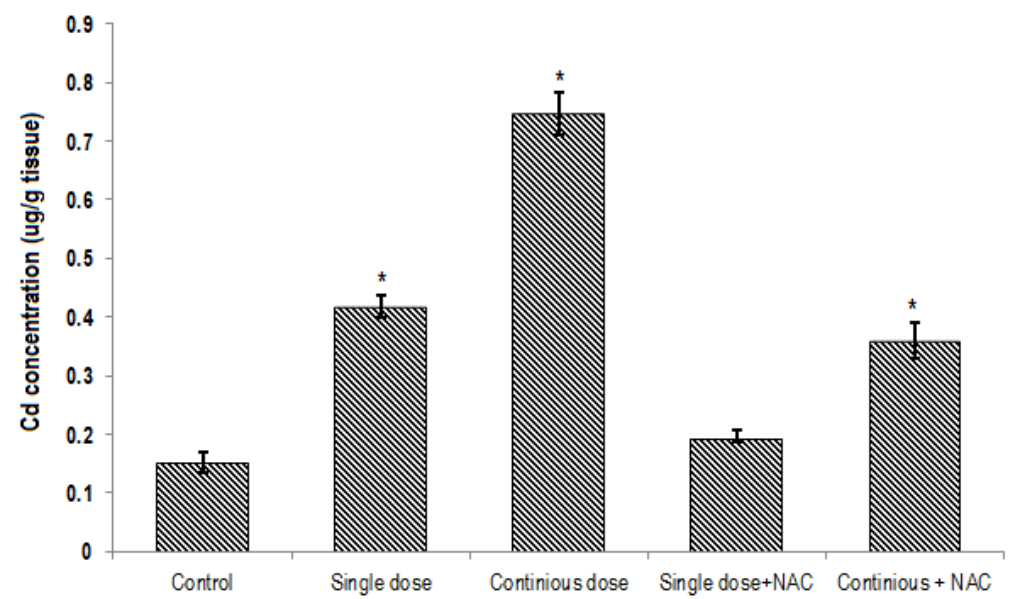

Figure 3. Comparison of the mean of Cd levels in the liver of rats in different groups. One-Way ANOVA: Post HocTukey test was applied to compare mean value of $\mathrm{Cd}$ between all groups.

${ }^{*} \mathrm{p}<0.001$ compared to control group.

Comparison of the mean contents of FRAP and MDA between all groups can be seen in (Table 1). Rats treated with continuous dose of $\mathrm{Cd}$ had significantly lower mean values of FRAP $(288.86 \pm 38.66 \mu \mathrm{g} / \mathrm{mL})$ compared to the other groups $(\mathrm{p}<0.001)$. NAC treatments significantly improved FRAP values in rats that exposed to continuous dose of Cd (from $288.86 \pm 38.66 \mu \mathrm{g} / \mathrm{mL}$ to $431.77 \pm 31.85 \mu \mathrm{g} / \mathrm{mL}$; $\mathrm{p}<0.001)$. Moreover, rats exposed to continuous dose of Cd had significantly higher MDA contents $(38.97 \pm 3.25 \mu \mathrm{g} / \mathrm{mL})$ than other groups $(\mathrm{p}<0.001)$. NAC treatments significantly decreased MDA values in rats that exposed to continuous dose of $\mathrm{Cd}$ (from $38.97 \pm 3.25 \mu \mathrm{g} / \mathrm{mL}$ to $26.89 \pm 2.54 \mu \mathrm{g} / \mathrm{mL} ; \mathrm{p}<0.001$ ).

The mean of Cd contents in the blood $(0.5 \pm 0.05 \mathrm{mg} / \mathrm{L}$; Figure 2$)$ and liver tissue $(0.74 \pm 0.08 \mu \mathrm{g} / \mathrm{g}$ tissue; Figure 3$)$ of rats exposed to continuous $\mathrm{Cd}$ was significantly higher compared to the other groups $(\mathrm{p}<0.001)$. NAC supplementation significantly decreased $\mathrm{Cd}$ concentrations in both serum and tissue samples of rats exposed to single or continuous $\mathrm{Cd}$. The mean concentration of $\mathrm{Cd}$ in the liver and serum of rats treated with $\mathrm{NAC}+$ single $\mathrm{Cd}(0.19 \pm 0.025 \mu \mathrm{g} / \mathrm{g}$ tissue and $0.0069 \pm 0.001 \mathrm{mg} / \mathrm{L}$, respectively) was relatively similar to that in control $(0.15 \pm 0.04 \mu \mathrm{g} / \mathrm{g}$ tissue and $0.007 \pm 0.001 \mathrm{mg} / \mathrm{L}$, respectively). Although NAC supplementation significantly decreased Cd levels in the liver and serum samples of rats that treated with continuous $\mathrm{Cd}(0.36 \pm 0.75 \mu \mathrm{g} / \mathrm{g}$ tissue and $0.016 \pm 0.005 \mathrm{mg} / \mathrm{L}$, respectively), its level was still greater than control group (Figures 2 and 3).

A significant difference was found in expression of Nrf2, NLRP3 and caspase1 genes between groups ( $\mathrm{p}<0.001)$. Continuous treatment of Cd significantly decreased the expression of Nrf2 gene (Table 2, Figure 4) and enhanced NLRP3 (Table 3, Figure 5) and Caspase 1 (Table 4, Figure 6) genes expression in the liver of rats. Compared to the control group, continuous dose treatment of Cd caused a significant decrease in Nrf2 expression by 2.46-fold ( $<<0.001)($ Table 2) and increased the expression of NLRP3 and caspase 1 genes by 3.13-fold $(\mathrm{p}<0.001)$ and 3.16-fold ( $<<0.001)$, respectively. In contrast, rats that received a combination of NAC and Cd showed a significant decrease in NLRP3 and caspase 1 and 
significant increase in Nrf2 expression in compare with animals that only treated with continuous Cd. Compared to rats that treated to continuous dose of $\mathrm{Cd}$, NAC supplementation enhanced the expression of Nrf2 by 1.67 -fold ( $\mathrm{p}<0.001)$ and reduced the expression of NLRP3 and caspase 1 genes by 1.39-fold $(\mathrm{p}<0.001)$ and 1.58-fold $(\mathrm{p}<0.001)$, respectively (Tables 2 $4)$.

Table 2: Comparison of the fold change ratio of the Nrf2 expression.

\begin{tabular}{llll}
\hline & Fold-change ratio & Up-/down-regulation & $P$-value \\
\hline Single vs control & 1.16 & Down-regulated & 0.074 \\
Continuous vs control & 2.46 & Down-regulated & $<0.001$ \\
NAC + single vs control & 1.08 & Up-regulated & 0.46 \\
NAC + continuous vs control & 1.47 & Down-regulated & $<0.05$ \\
Continuous vs Single & 2.11 & Down-regulated & $<0.001$ \\
Single vs NAC + continuous & 1.26 & Up-regulated & 0.015 \\
Single + NAC vs single & 1.26 & Up-regulated & 0.012 \\
Single + NAC vs continuous & 2.67 & Up-regulated & $<0.001$ \\
Single + NAC vs NAC + continuous & 1.60 & Up-regulated & $<0.001$ \\
Continuous + NAC vs continuous & 1.67 & Up-regulated & $<0.001$ \\
\hline${ }^{*}$ p $<0.05$ is considered as significant; One-Way ANOVA: Post Hoc-Tukey test was applied to compare mean value of Nrf2 expression pattern between all groups.
\end{tabular}

Table 3: Comparison of the fold change ratio of the NLRP3 expression

\begin{tabular}{llll}
\hline & Fold-change ratio & Up-/down-regulation & $P$-value \\
\hline Single vs control & 1.30 & Up-regulated & 0.012 \\
Continuous vs control & 3.13 & Up-regulated & $<0.001$ \\
NAC + single vs control & 1.10 & Up-regulated & 0.73 \\
NAC + continuous vs control & 2.26 & Up-regulated & $<0.001$ \\
Continuous vs Single & 2.40 & Up-regulated & $<0.001$ \\
Single vs NAC + continuous & 1.73 & Down-regulated & $<0.001$ \\
Single + NAC vs single & 1.18 & Down-regulated & 0.16 \\
Single + NAC vs continuous & 2.84 & Down-regulated & $<0.001$ \\
Single + NAC vs NAC + continuous & 2.04 & Down-regulated & $<0.001$ \\
Continuous + NAC vs continuous & 1.39 & Down-regulated & $<0.001$ \\
\hline
\end{tabular}

${ }^{*} \mathrm{p}<0.05$ is considered as significant; One-Way ANOVA: Post Hoc-Tukey test was applied to compare mean value of NLRP3 expression pattern between all groups.

Table 4: Comparison of the fold change ratio of the caspase1 expression

\begin{tabular}{llll}
\hline & Fold-change ratio & Up-/down-regulation & $P$-value \\
\hline Single vs control & 1.43 & Up-regulated & 0.09 \\
Continuous vs control & 3.16 & Up-regulated & $<0.001$ \\
NAC + single vs control & 1.23 & Up-regulated & 0.62 \\
NAC + continuous vs control & 2.00 & Up-regulated & $<0.001$ \\
Continuous vs Single & 2.22 & Up-regulated & $<0.001$ \\
Single vs NAC + continuous & 1.40 & Down-regulated & 0.011 \\
Single + NAC vs single & 1.16 & Down-regulated & 0.73 \\
Single + NAC vs continuous & 2.58 & Down-regulated & $<0.001$ \\
Single + NAC vs NAC + continuous & 1.63 & Down-regulated & 0.001 \\
Continuous + NAC vs continuous & 1.58 & Down-regulated & $<0.001$ \\
\hline${ }^{*}<0.05$ is considered as significant; One-Way ANOVA: Post Hoc-Tukey test was applied to compare mean value of caspase 1 expression pattern between all \\
groups.
\end{tabular}




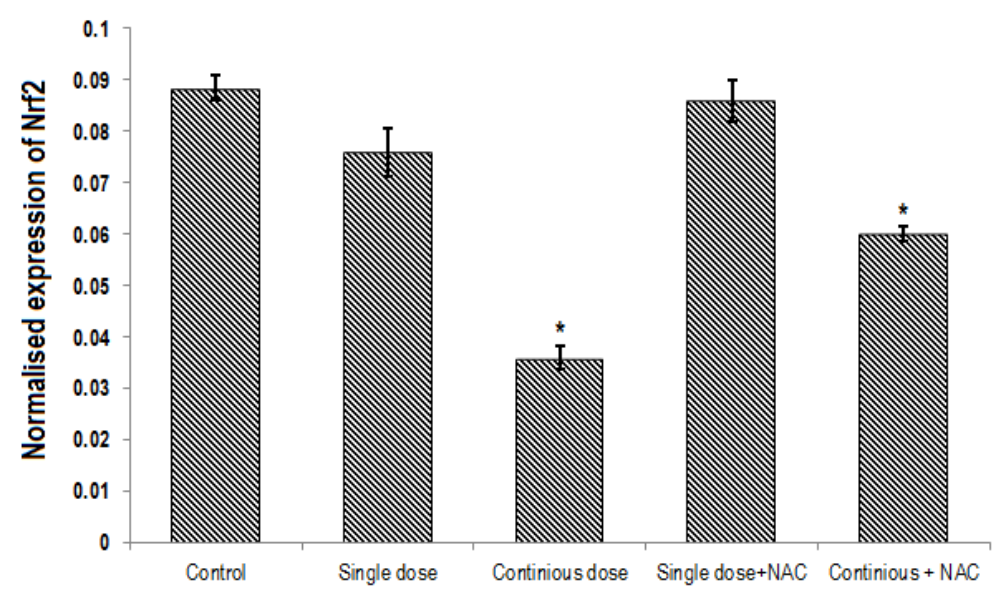

Figure 4. Comparison of the normalized expression of Nrf2 between different groups. One-Way ANOVA: Post HocTukey test was applied to compare normalized expression of Nrf2 between all groups. * $\mathrm{p}<0.001$ compared to control group.

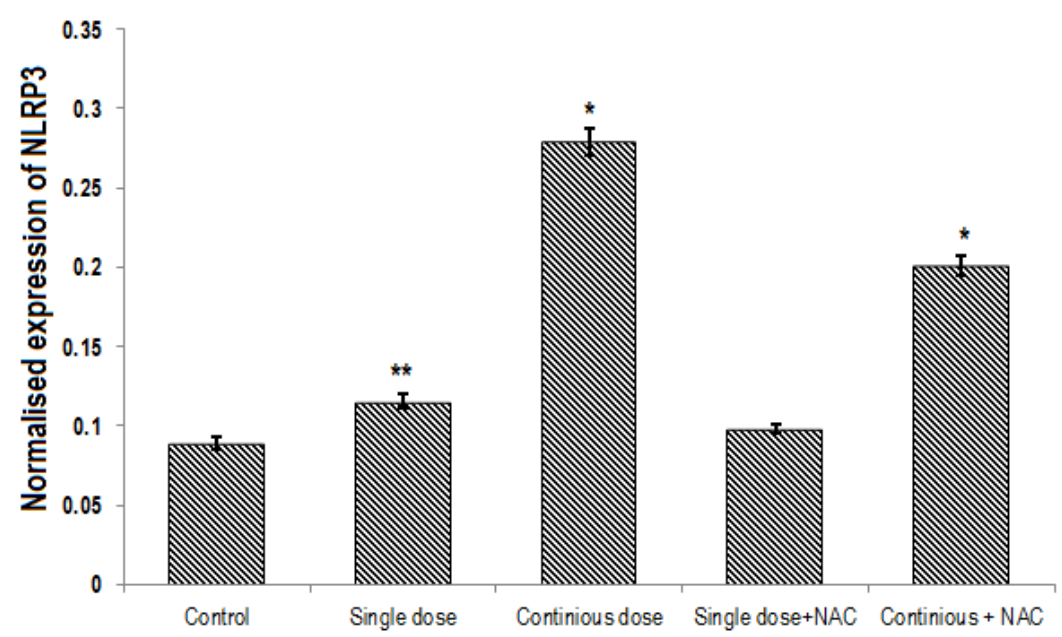

Figure 5. Comparison of the normalized expression of NLRP3 between different groups. One-Way ANOVA: Post HocTukey test was applied to compare normalized expression of NLRP3 between all groups. ${ }^{*}<0.001$ and ${ }^{* *} \mathrm{p}<0.05$ compared to control group.

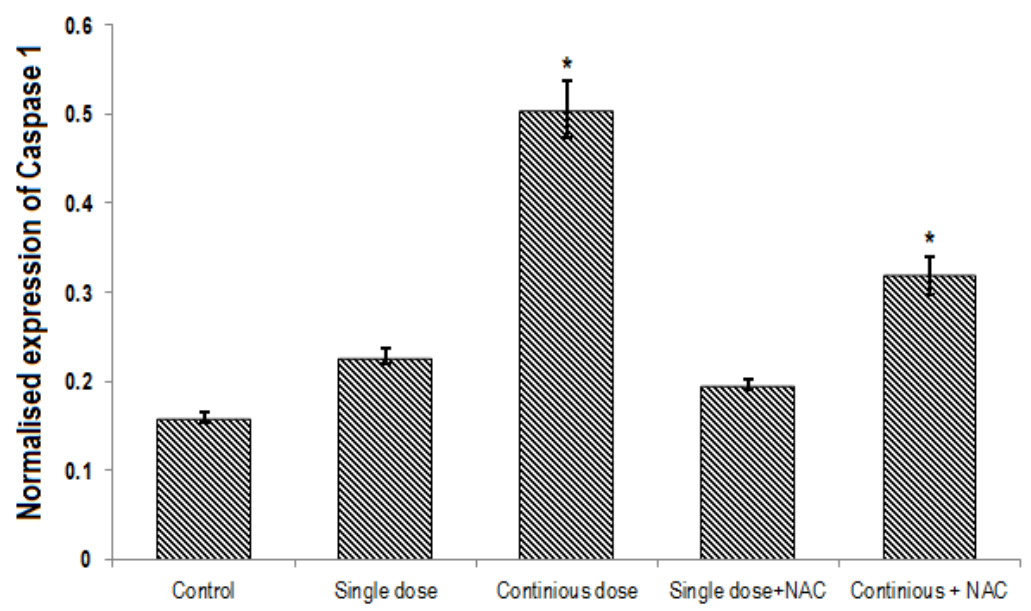

Figure 6. Comparison of the normalized expression of Caspase 1 between different groups. One-Way ANOVA: Post Hoc-Tukey test was applied to compare normalized expression of Caspase 1 between all groups. ${ }^{*} \mathrm{p}<0.001$ compared to control group. 


\section{Discussion}

In this study, we considered the effect of NAC supplementation on histological changes, oxidative stress, as well as genes expression of Nrf2, NLRP3 and caspase 1 in the liver tissue of rats exposed to single or continuous dose treatment of Cd. Our findings have shown that Cd exposure, especially at continuous phase, is significantly associated with Cd accumulation in serum and liver tissue, depletion of total antioxidants, and enhanced level of MDA in the liver tissue of exposed animals. Since Nrf2 plays a key role in emerging regulator of cellular resistance to oxidants and controls expression of an array of antioxidant response against oxidants, its down-regulation may be associated with accumulation of oxidants and oxidative stress. On the other hand, given the crucial role of NLRP3 and caspase 1 in inflammation and apoptosis, overexpression of these genes can trigger immune responses and induce cells apoptosis. Therefore, our findings support the idea that toxicological effect of Cd on liver tissue may be mediated by down-regulation of Nrf2, up-regulation of NLRP3 and caspase 1, and consequently induction of antioxidant depletion, oxidative stress, inflammation, and hepatic cells apoptosis.

Many studies reported that $\mathrm{Cd}$ exposure has genotoxicity and cytotoxicity effects on different tissues and induces oxidative stress and inflammation in different tissues. Nazimabashir et al. [24] revealed that $\mathrm{Cd}(5 \mathrm{mg} / \mathrm{kg} / \mathrm{BW} \mathrm{PO})$ significantly increases oxidative stress biomarkers in the cardiac tissue of exposed rats. Furthermore, Cd exposure significantly enhanced the content of inflammatory cytokines such as TNF- $\alpha$ and IL-6, as well as apoptotic biomarkers such as caspase 3, cytochrome C, Bax, Bcl-2 in the heart tissue [24]. Another study reported that Cd treatment (5 mg/kg/BW PO) is associated with a significant enhancement of oxidative stress biomarkers and reduction of enzymatic and non-enzymatic antioxidant activities in erythrocytes [25]. A recent study has demonstrated that single treatment of Cd (15 and $30 \mathrm{mg} / \mathrm{kg} / \mathrm{BW})$ significantly decreases the content of SH groups and subsequently increases oxidative stress biomarkers such as MDA and oxidized protein products in the liver, kidney and blood samples of exposed rats [26]. DNA fragmentation and lung epithelial cells apoptosis was reported in rats exposed to $\mathrm{Cd}$ in acute phase (1-30 $\mu \mathrm{M})$ [27]. Yuan et al. [28] found that Cd treatment induces apoptosis of cerebral cortical neurons via induction of cytochrome oxidase dysfunction, massive production of ROS, and elevation of caspase- 9 and caspase- 3 activity.

Several lines of studies reported that Cd decreases the expression of Nrf2, but induces the expression of NLRP3 and apoptosis biomarkers. For example, Chen and Shaikh showed that $\mathrm{Cd}$ treatment is associated with down-regulation of Nrf2 and consequently cells apoptosis in in kidney cell line [29]. More recently, Liu et al. [30] found that Cd exposure causes liver cells injury through down-regulation of Nrf2 and up-regulation of NLRP3 which is in line with the findings of our study. In another study, Montes et al. [31] showed that Cd exposure down-regulates the expression of Nrf2 in the heart, lung, kidney, liver, and brain of rats. Therefore, these data indicate that depletion of antioxidants, oxidative stress, inflammation and overexpression of apoptotic mediators may be the main mechanisms of Cd toxicity on liver tissue. More importantly, increased expression of Nrf2 can be considered as part of protective mechanism against cadmium-induced toxicity.

According to these findings and the concepts of Cd cytotoxicity on the liver tissue, these might make a wise basis for the use of antioxidants or compounds that could protect hepatocytes from oxidative stress and apoptosis. Here, we considered the effect of NAC treatment to mitigate oxidative stress caused by Cd effects. In our study, NAC treatment significantly decreased hepatic cells injuries caused by $\mathrm{Cd}$. This effect was associated with a significant increase in total antioxidant capacity and a significant decrease in MDA in the liver tissue. Interestingly, we found that NAC treatment modulated expression of Nrf2, NLRP3 and caspase 1 genes in the liver tissue of Cd-treated rats. Although the level of oxidative stress, inflammation and hepatic cells apoptosis biomarkers in the liver of rats that exposed to chronic dose of Cd + NAC were somewhat high, NAC improved these abnormalities in this group compared to rats that only treated with continuous dose of $\mathrm{Cd}$. These data indicate that NAC can be helpful in mitigating oxidative stress, inflammation and hepatic cells apoptosis in the liver tissue through the improvement of Nrf2 and reducing expression of NLRP3 and caspase 1 genes. He et al. [32] demonstrated that geniposide decreases Cd-induced oxidative stress and apoptosis via induction of Nrf2 gene expression. Park and Seo [33] showed that Nrf2 protects tissues from oxidative stress-induced DNA damage and suppresses the carcinogenicity of cadmium. Some studies revealed that NAC attenuates inflammation and oxidative stress by diminishing ROS production and apoptosis, as well as down-regulation of inflammatory cytokines and increasing of antiinflammatory mediators and antioxidants contents. Wang et al. [34] reported that NAC treatment no only decreases oxidative stress biomarkers and expression of apoptosis biomarkers such as Bax and Caspases, but also it improves the activity of glutathione peroxidase (GPX) and glutathione reductase (GR) in vitro. Al-Nahdi et al. [35] revealed that NAC decreases streptozotocin-induced oxidative stress, inhibits DNA damage and expression of apoptotic proteins in pancreatic $\beta$-cells. In another research, Chen et al. [36] found that NAC treatment significantly prevented Cd-induced ROS production and attenuated $\mathrm{Cd}$-induced brain damage or neuronal cell death by increasing the activities of $\mathrm{Cu} / \mathrm{Zn}$-superoxide dismutase, catalase and glutathione peroxidase, as well as the level of glutathione in the brain. The protective effect of NAC against cadmium-induced oxidative stress and apoptosis in other cell types such as germ cells [37], rat normal liver cells [38], Leydig cells [39] was previously reported. Our observation agreed with these results. According to previous accomplished data and our findings, downregulation of Nrf2 and overexpression of NLRP3 and caspase 1 may be a main mechanism of Cd 
toxicity on liver tissue. NAC protects liver tissue against Cd-induced oxidative injuries through improvement of Nrf2 and reduction of NLRP3 and caspase 1 genes.

\section{Conclusions}

The findings of the current study revealed that $\mathrm{Cd}$ exposure, especially continuous exposure to $\mathrm{Cd}$, is strongly associated with $\mathrm{Cd}$ accumulation, antioxidants depletion, oxidative stress, and inflammation in the liver tissue. Downregulation of Nrf2 and overexpression of NLRP3 and caspase 1 seem to be a main mechanism of Cd toxicity on liver tissue. NAC protects liver tissue against Cd-induced oxidative injuries via enhancement of Nrf2 expression and reduction of NLRP3 and caspase 1 genes.

\section{Acknowledgement}

This work was supported by AJA University of Medical Sciences.

\section{Conflict of interest}

The authors declare that they have no conflict of interest.

\section{CRediT author statement}

JA: Conceptualization, ABB: Data curation, Writing- Original draft preparation. MRP: Visualization, Investigation; PE: Reviewing and Editing.

\section{ORCID}

Asghar Beigi Harchegani: 0000-0003-4054-4136

Hanieh Akhlaghi: 0000-0001-5613-038X

Zhaleh Mohsenifar: 0000-0002-7766-7570

Pirooz Ebrahimi: 0000-0002-8612-4893

Mohammad Reza Parvizi: 0000-0002-3778-3550

\section{References}

[1] García-Esquinas E, Pollan M, Tellez-Plaza M, Francesconi KA, Goessler W, Guallar E, et al. Cadmium exposure and cancer mortality in a prospective cohort: the strong heart study. Environ Health Perspect, 2014;122(4):363-370. https://doi.org/10.1289/ehp.1306587

[2] Barbier O, Jacquillet G, Tauc M, Cougnon M, Poujeol P. Effect of heavy metals on, and handling by, the kidney. Nephron Physiol 2005;99(4):105-110. https://doi.org/10.1159/000083981

[3] Foulkes EC. Interactions between metals in rat jejunum: implications on the nature of cadmium uptake. Toxicology 1985; 37(1-2):117-125. https://doi.org/10.1016/0300-483X(85)90118-0

[4] Vestena S, Cambraia J, Ribeiro C, Oliveira JA, Oliva MA. Cadmium-induced oxidative stress and antioxidative enzyme response in water hyacinth and salvinia. Braz. J Plant Physiol 2011;23(2):131-139. https://doi.org/10.1590/S167704202011000200005

[5] Liu T, He W, Yan C, Qi Y, Zhang Y. Roles of reactive oxygen species and mitochondria in cadmium-induced injury of liver cells. TIH 2010;27(3):249-256. https://doi.org/10.1177/0748233710386408

[6] Liu J, Qu W, Kadiiska MB. Role of oxidative stress in cadmium toxicity and carcinogenesis. Toxicol Appl Pharmacol 2009; 238(3):209-214. https://doi.org/10.1016/j.taap.2009.01.029

[7] Kelley N, Jeltema D, Duan Y, He Y. The NLRP3 inflammasome: an overview of mechanisms of activation and regulation. Int J Mol Sci 2019;20(13):3328. https://doi.org/10.3390/ijms20133328

[8] Hemalatha P, Reddy AG, Reddy YR, Shivakumar P. Evaluation of protective effect of N-acetyl cysteine on arsenicinduced hepatotoxicity. Journal of natural science, biology, and medicine 2013;4(2):393. http://doi.org/10.4103/0976$\underline{9668.116986}$

[9] Dekhuijzen PNR. Antioxidant properties of N-acetylcysteine: their relevance in relation to chronic obstructive pulmonary disease. European Respiratory Journal 2004;23(4):629-636. http://doi.org/10.1183/09031936.04.00016804

[10] Koyu A, Gokcimen A, Ozguner F, Bayram DS, Kocak A. Evaluation of the effects of cadmium on rat liver. Mol Cell Biochem 2006;284(1):81-85. https://doi.org/10.1007/s11010-005-9017-2 
[11] Olisekodiaka MJ, Igbeneghu CA, Onuegbu AJ, Oduru R, Lawal AO. Lipid, lipoproteins, total antioxidant status and organ changes in rats administered high doses of cadmium chloride. Med Princ Pract 2012;21(2):156-159. https://doi.org/10.1159/000333385

[12] Boujelben M, Ghorbel F, Vincent C, Mkni-Ayadi F, Guermazi F, Croute F, et al. Lipid peroxidation and HSP72/73 expression in rat following cadmium chloride administration: interactions of magnesium supplementation. Exp Toxicol Pathol 2006;57(5-6):437-443. https://doi.org/10.1016/j.etp.2006.02.012

[13] Kotsonis FN, Klaassen CD. Toxicity and distribution of cadmium administered to rats at sublethal doses. Toxicol Appl Pharmacol 1977;41(3):667-680. https://doi.org/10.1016/S0041-008X(77)80020-3

[14] Nasiadek M, Danilewicz M, Klimczak M, Stragierowicz J, Kilanowicz A. Subchronic exposure to cadmium causes persistent changes in the reproductive system in female wistar rats. Oxidative medicine and cellular longevity, 2019. https://doi.org/10.1155/2019/6490820

[15] Ma Z, Chu L, Liu H, Wang W, Li J, Yao W, et al. Beneficial effects of paeoniflorin on non-alcoholic fatty liver disease induced by high-fat diet in rats. Sci Rep 2017;7(1):1-10. https://doi.org/10.1038/srep44819

[16] Benzie IFF, Lipid peroxidation: a review of causes, consequences, measurement and dietary influences. Int J Food Sci Nutr 1996;47(3):233-261. https://doi.org/10.3109/09637489609012586

[17] HOSSEINZADEH KA, Pouramir M, Tahmasbpour MI. Seminal plasma total antioxidants capacity of the infertile smoker and nonsmoker men. SHAHID CHAMRAN UNIVERSITY JOURNAL OF SCIENCE 2008;19:124-131.

[18] Rao B, Soufir JC, Martin M, David G. Lipid peroxidation in human spermatozoa as related to midpiece abnormalities and motility. Gamete Res 1989;24(2):127-34. https://doi.org/10.1002/mrd.1120240202

[19] Colagar AH, Pouramir M, Marzony ET, Jorsaraei SGA. Relationship between seminal malondialdehyde levels and sperm quality in fertile and infertile men. Brazilian Archives of Biology and Technology 2009;52:1387-1392. https://doi.org/10.1590/S1516-89132009000600010

[20] Yamashita Y, Ueyama T, Nishi T, Yamamoto Y, Kawakoshi A, Sunami S, et al. Nrf2-inducing anti-oxidation stress response in the rat liver - new beneficial effect of lansoprazole. PLoS One 2014;9(5):e97419. https://doi.org/10.1371/journal.pone.0097419

[21] Chen X, Li H, Wang K, Liang X, Wang W, Hu X, et al. Aerobic exercise ameliorates myocardial inflammation, fibrosis and apoptosis in high-fat-diet rats by inhibiting P2X7 purinergic receptors. Front Physiol 2019;10:1286. https://doi.org/10.3389/fphys.2019.01286

[22] Zhang XH, Li ML, Wang B, Guo MX, Zhu RM. Caspase-1 inhibition alleviates acute renal injury in rats with severe acute pancreatitis. World J Gastroenterol 2014;20(30):10457. https://doi.org/10.3748/wjg.v20.i30.10457

[23] Livak KJ, Schmittgen TD. Analysis of relative gene expression data using real-time quantitative PCR and the 2(-Delta Delta C(T)) Method. Methods 2001;25(4):402-408. https://doi.org/10.1006/meth.2001.1262

[24] Manoharan V, Miltonprabu S. Cadmium induced cardiac oxidative stress in rats and its attenuation by GSP through the activation of Nrf2 signaling pathway. Chem Biol Interact 2015;242:179-193. https://doi.org/10.1016/j.cbi.2015.10.005

[25] Nazima B, Manoharan V, Miltonprabu S. Oxidative stress induced by cadmium in the plasma, erythrocytes and lymphocytes of rats: Attenuation by grape seed proanthocyanidins. Hum Exp Toxicol 2016;35(4):428-447. https://doi.org/10.1177/0960327115591376

[26] Andjelkovic M, Buha Djordjevic A, Antonijevic E, Antonijevic B, Stanic M, Kotur-Stevuljevic J, et al. Toxic effect of acute cadmium and lead exposure in rat blood, liver, and kidney. Int. J. Environ. Res. Public Health 2019;16(2):274. https://doi.org/10.3390/ijerph16020274

[27] Hart BA, Lee CH, Shukla GS, Shukla A, Osier M, Eneman JD, et al. Characterization of cadmium-induced apoptosis in rat lung epithelial cells: evidence for the participation of oxidant stress. Toxicology 1999;133(1):43-58. https://doi.org/10.1016/S0300-483X(99)00013-X

[28] Yuan Y, Jiang CY, Xu H, Sun Y, Hu FF, Bian JC, et al. Cadmium-induced apoptosis in primary rat cerebral cortical neurons culture is mediated by a calcium signaling pathway. PLOS ONE 2013;8(5):e64330. https://doi.org/10.1371/journal.pone.0064330

[29] Chen J, Shaikh ZA. Activation of Nrf2 by cadmium and its role in protection against cadmium-induced apoptosis in rat kidney cells. Toxicol Appl Pharmacol 2009;241(1):81-89. https://doi.org/10.1016/j.taap.2009.07.038 
[30] Liu C, Zhu Y, Lu Z, Guo W, Tumen B, He Y, et al. Cadmium induces acute liver injury by inhibiting Nrf2 and the role of NF- $\kappa B$, NLRP3, and MAPKs Signaling Pathway. Int J Environ Res Public Health 2020;17(1):138. https://doi.org/10.3390/ijerph17010138

[31] Montes S, Juárez-Rebollar D, Nava-Ruíz C, Sánchez-García A, Heras-Romero Y, Rios C, et al. Immunohistochemical study of Nrf2-antioxidant response element as indicator of oxidative stress induced by cadmium in developing Rats. Oxidative Medicine and Cellular Longevity 2015;570650. https://doi.org/10.1155/2015/570650

[32] He T, Shen H, Zhu J, Zhu Y, He Y, Li Z, et al. Geniposide attenuates cadmium-induced oxidative stress injury via Nrf2 signaling in osteoblasts. Molecular Medicine Reports 2019;20(2):1499-1508. https://doi.org/10.3892/mmr.2019.10396

[33] Park JY, Seo YR. The protective role of Nrf2 in cadmium-induced DNA damage. Molecular \& Cellular Toxicology 2011; 7(1):61. https://doi.org/10.1007/s13273-011-0009-x

[34] Wang J, Li M, Zhang W, Gu A, Dong J, Li J, et al. Protective effect of n-acetylcysteine against oxidative stress induced by zearalenone via mitochondrial apoptosis pathway in SIEC02 Cells. Toxins (Basel) 2018;10(10):407. https://doi.org/10.3390/toxins10100407

[35] Al-Nahdi AM, John A, Raza H. Cytoprotective effects of N-acetylcysteine on streptozotocin- induced oxidative stress and apoptosis in RIN-5F pancreatic $\beta$-cells. Cellular Physiol Biochem 2018;51(1):201-216.

https://doi.org/10.1159/000495200

[36] Chen S, Ren Q, Zhang J, Ye Y, Zhang Z, Xu Y, et al. N-acetyl-L-cysteine protects against cadmium-induced neuronal apoptosis by inhibiting ROS-dependent activation of A kt/mTOR pathway in mouse brain. Neuropathol Appl Neurobiol 2014;40(6):759-777. https://doi.org/10.1111/nan.12103

[37] Ji YL, Wang H, Zhang C, Zhang Y, Zhao M, Chen YH, et al. N-acetylcysteine protects against cadmium-induced germ cell apoptosis by inhibiting endoplasmic reticulum stress in testes. Asian J Androl 2013;15(2):290. https://doi.org/10.1038/aja.2012.129

[38] Odewumi CO, Badisa VL, Le UT, Latinwo LM, Lkediobi CO, Badisa RB, et al. Protective effects of N-acetylcysteine against cadmium-induced damage in cultured rat normal liver cells. Int J Mol Med 2011;27(2):243-248. https://doi.org/10.3892/ijmm.2010.564

[39] Khanna S, Mitra S, Lakhera PC, Khandelwal S. N-acetylcysteine effectively mitigates cadmium-induced oxidative damage and cell death in Leydig cells in vitro. Drug Chem Toxicol 2016;39(1):74-80.

https://doi.org/10.3109/01480545.2015.1028068 